\title{
Modern extraction techniques and their impact on the pharmacological profile of Serenoa repens extracts for the treatment of lower urinary tract symptoms
}

\author{
Celeste De Monte ${ }^{1}$, Simone Carradori ${ }^{1}$, Arianna Granese ${ }^{1}$, Giovanni Battista Di Pierro ${ }^{2 *}$, Costantino Leonardo ${ }^{2}$ \\ and Cosimo De Nunzio ${ }^{3}$
}

\begin{abstract}
Background: Bioactive compounds from plants (i.e., Serenoa repens) are often used in medicine in the treatment of several pathologies, among which benign prostatic hyperplasia (BPH) associated to lower urinary tract symptoms (LUTS).

Discussion: There are different techniques of extraction, also used in combination, with the aim of enhancing the amount of the target molecules, gaining time and reducing waste of solvents. However, the qualitative and quantitative composition of the bioactives depends on the extractive process, and so the brands of the recovered products from the same plant are different in terms of clinical efficacy (no product interchangeability among different commercial brands).
\end{abstract}

Summary: In this review, we report on several and recent extraction techniques and their impact on the composition/biological activity of S. repens-based available products.

Keywords: Benign prostatic hyperplasia, Serenoa repens, Extraction techniques, Supercritical fluid extraction, Lipidosterolic composition, Content standardization

\section{Background}

Benign prostatic hyperplasia (BPH) is a significant health concern and increases in prevalence as the population ages. Symptomatic BPH represents the most common urologic disease among elderly males, affecting about onequarter of men in their '50s, one-third of men in their '60s, and about half of octogenarians. BPH is considered a chronic disease with early initiation and slow progression. $\mathrm{BPH}$ starts as a simple micro nodular hyperplasia and evolves into a macroscopic nodular enlargement that may result in bladder prostatic obstruction (BPO), causing lower urinary tract symptoms (LUTS) [1,2]. When considering options for managing LUTS, which may suggest $\mathrm{BPO}$, the short term goal is to improve the individual's

\footnotetext{
* Correspondence: gb.dipierro@libero.it

${ }^{2}$ Department of Obstetrics, Gynecology and Urology, Sapienza University of Rome, Viale del Policlinico 155, Rome 00161, Italy

Full list of author information is available at the end of the article
}

quality of life by relieving symptoms, however, the aim should be to prevent or reduce the worsening of symptoms over longer term and limiting $\mathrm{BPH}$ progression [3]. Medical treatment options of LUTS/BPO include $\alpha 1$-adrenoceptor antagonists, $5 \alpha$-reductase inhibitors, anti-cholinergic agents, phosphodiesterase 5 inhibitors and plant extracts. Although the European Association of Urology is unable to make specific recommendations about plant extracts treatment in patients with LUTS/ $\mathrm{BPH}$ because of the heterogeneity of the marketed products and the methodological problems associated with meta-analysis, their use in clinical practice is rising with an increased global prescription index, particularly in some European countries (Belgium, Hungary, Poland, France) $[2,4,5]$. Furthermore, the treatment of BPH with $\alpha$-blockers and $5 \alpha$-reductase inhibitors could play an important role in the alteration of sexual functions leading to ejaculatory and erectile disorders [6]. To avoid 
this issue, natural products derived from plants have been using for treating BPH, especially extracts of Serenoa repens (saw palmetto) obtained from the American dwarf palm [7-9].

Nowadays, a lot of extractive strategies with differences in terms of methodology, time, temperature, pressure and solvents have been developed, also used in combination with other techniques in order to improve the recovery and, consequently, the pharmacological profile of their extracts. However, as a consequence of the differences among the extractive processes used by several companies, there is a discrepancy in the qualitative and quantitative composition of the extracts obtained from the same plant. Hence, each brand is different in quality and efficacy for the content of the bioactive compounds with repercussions on the beneficial effects for patients in response to clinical trials and treatments [10].

\section{Discussion}

The aim of this review is the evaluation of the available evidence on plant extraction and its possible clinical implications on $S$. repens therapeutic efficacy.

\section{Serenoa repens as a standard reference material (SRM)}

The knowledge of the exhaustive quali-quantitative composition of $S$. repens extracts is warranted not only due to the multiple variables associated to different extraction techniques, but also due to the not yet fully understood pharmacological profile of each active principle.

For this reason, the validation of appropriate analytical methods, to develop standard reference materials for selected dietary supplements, have been regulated by the National Institute of Health's Office of Dietary Supplements and the Food and Drug Administration's Center for Drug Evaluation and Research in collaboration with the National Institute of Standards and Technology (NIST) [11].

NIST, as a non-regulatory federal agency of USA, supports accurate and compatible measurements by certifying and providing over 1300 Standard Reference Materials ${ }^{\oplus}$ (SRMs) with well-characterized composition or properties. Each NIST Standard Reference Material $^{\circledR}$ is supplied with a Certificate of Analysis and/or a Materials Safety Data Sheet. In addition, NIST has published many articles and practice guides that describe the development, analysis, traceability and use of SRMs. Certified concentration values are usually determined by two or more independent methods, which could be combined with data from other laboratories.

In the case of saw palmetto, two reference materials have been reported, SRM $3250 \mathrm{~S}$. repens ground fruit and SRM 3251 S. repens extract. SRM 3250 has certified concentration values for specific phytosterols, and fatty acids (free or as triglycerides). On the other hand, the extract SRM 3251 has certified concentration values for phytosterols, fatty acids (free or as triglycerides), $\beta$-carotene and its isomers, and $\gamma$ - and $\delta$-tocopherol.

For SRM 3250 three extraction procedures and conditions for each procedure were evaluated including PFE (pressurized fluid extraction), Soxhlet extraction (with dichloromethane), and sonication. PFE and Soxhlet extraction gave the highest amounts of extracted fatty acids from the ground fruit. In the case of PFE (conditions: solvent mixture of 4:1 (v/v) of hexane/acetone with a four static cycle extraction at $125^{\circ} \mathrm{C}$ and $10.4 \mathrm{MPa}$ ), the choice of solvent, temperature of extraction, and pressure of extraction did not have significant effects on the composition of the extracted fractions. The solvent choice also did not have a deep impact on the efficiency of the Soxhlet extraction, although the duration of the extraction time was critical (at least $40 \mathrm{~h}$ ). Conversely, SRM 3251 has been obtained as a supercritical $\mathrm{CO}_{2}$ extract and analyzed with respect to the corresponding extracts obtained for SRM 3250.

As reported in Table 1, the concentrations of the fatty acids as triglycerides were 6-25 times higher in SRM 3251 compared with SRM 3250. In general, the concentration of each fatty acid as a triglyceride was higher than the corresponding free fatty acid for both extracts. The concentration of linoleic and $\alpha$-linoleic acid in SRM 3250 was approximately six times lower than in SRM 3251. Linoleic and $\alpha$-linolenic acids were also lower in concentration as free fatty acids in both SRM 3250 and SRM 3251 as compared with the corresponding fatty acids as triglycerides.

These SRMs could also furnish appropriate reference materials to make comparisons among dietary supplements. In fact, SRM 3251 has the second highest concentration of linoleic acid, as regards the triglycerides, compared with the other available SRMs (i.e., fish oil and tissues), and the highest concentration of $\alpha$-linolenic acid. As regards the phytosterols content, in both SRMs, campesterol, $\beta$-sitosterol and stigmasterol have certified concentration values (higher in SRM 3251 than SRM 3250). Furthermore, $\beta$-carotene $(46.8 \mu \mathrm{g} / \mathrm{g}), \gamma$-tocopherol $(280 \mu \mathrm{g} / \mathrm{g})$ and $\delta$-tocopherol $(35.3 \mu \mathrm{g} / \mathrm{g})$ were also quantified.

\section{Extraction techniques}

Many plants possess bioactive metabolites that can be used as therapeutic agents for the treatment of human pathologies like BHP associated to LUTS. Because of the very low concentrations of therapeutic compounds in plants, their exhaustive recovery becomes a crucial issue in order to obtain high yields of the products with the use of an extractive method that should be reproducible, time saving and eco-friendly. Furthermore, in the choice of the extractive method, it is important to keep in mind 
Table 1 Composition of Serenoa repens extracts as standard reference materials

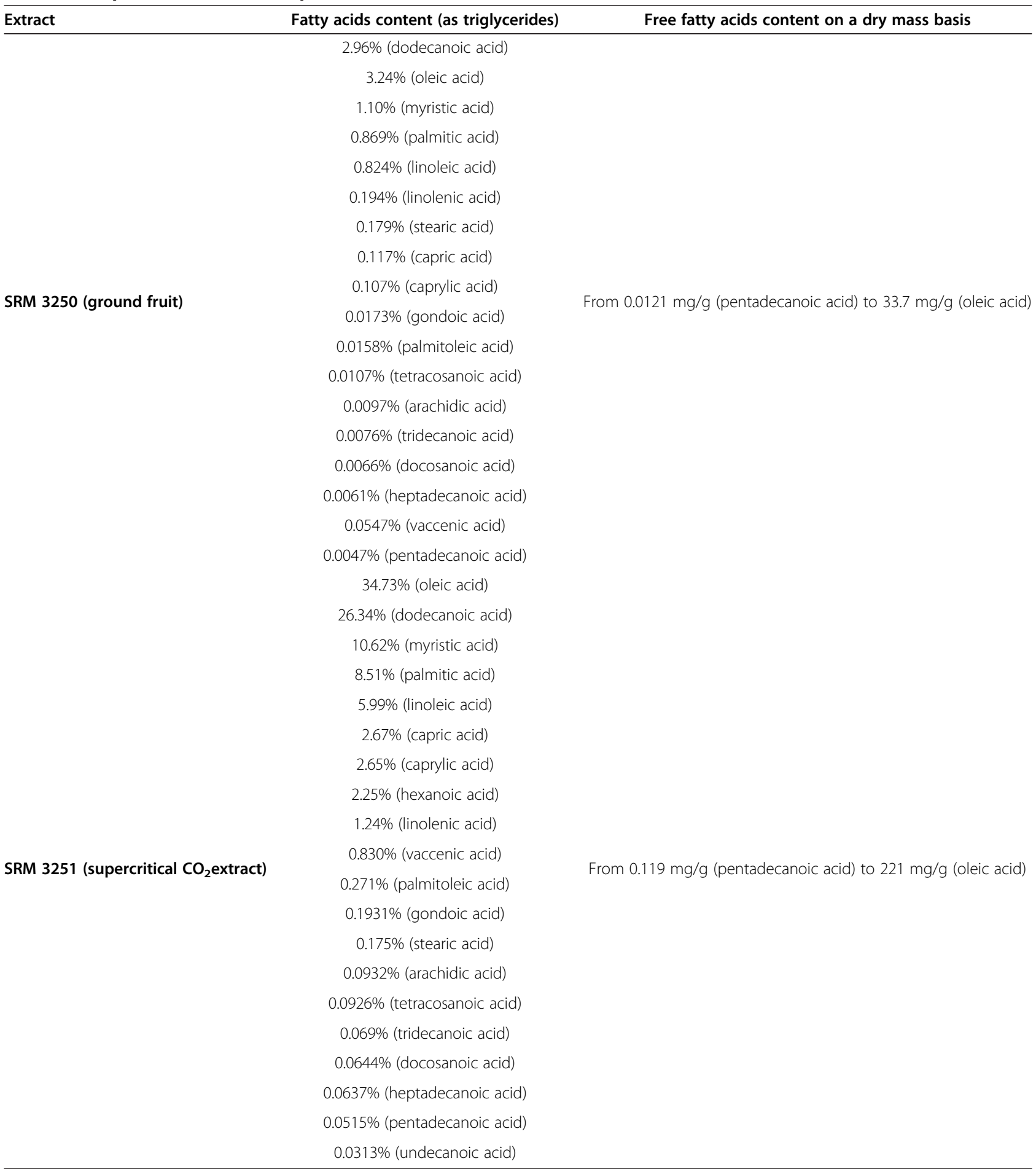

the thermolability of the active molecules, hence the temperature and the other parameters should be optimized. For having an efficient process, three important factors must be mainly considered: the sample matrix, the type and the localization of bioactive compounds within the matrix. In fact, the target compound firstly must be removed from the site in which it is placed and then it must diffuse towards the extraction phase to be finally collected.

We briefly report on classical and innovative extraction techniques which have been or could be applied to obtain $S$ repens extracts enriched by specific active principles. 


\section{Solvent extraction}

According to the solubility of the bioactive compounds there are a large number of inorganic, organic, polar and non-polar solvents to perform a good extraction, also in combination among them. If the substance of our interest is lipophilic, the organic solvents of choice will be nonpolar, ranging from those with a very low polarity such as hexane, to those that are less non-polar like chloroform and dichloromethane. For example, the apolar solvents cyclohexane, hexane, toluene, benzene, ether, chloroform and ethyl acetate are currently used to extract alkaloids, coumarins, fatty acids (FAs), flavonoids and terpenoids. On the contrary, for hydrophilic compounds the choice will fall on a polar solvent which may be non-protic such as acetone, or protic such as ethanol, methanol or even water. In fact acetone, acetonitrile, butanol, propanol and ethanol are the solvents for the extraction of flavonols, lectins, alkaloids, quassinoids, flavones, polyphenols, tannins and saponins. One of the major pros of this procedure is the use of simple equipment and its limited cost.

\section{Microwave-assisted extraction}

Microwave-assisted extraction (MAE) is an extractive method based on the utilization of microwave energy that is produced when the perpendicular oscillation between the electric and the magnetic fields generates electromagnetic radiations with a frequency ranging from 0.3 to $300 \mathrm{GHz}$. If the microwave goes through and interacts with a substance there is a production of heat whose intensity depends on the absorption of the energy by the material and the dissipation of the resulting heat [12].

MAE techniques can be classified according to the pressure through which they operate: higher than the atmospheric pressure (closed MAE system) and lower than the atmospheric pressure (open MAE system). As regards closed systems, the temperature is set over the boiling point of the solvent and the pressure is under control to avoid an excessive development. Among the closed systems we can enumerate high pressure microwaveassisted extraction (HPMAE) which uses high pressure and temperature in order to enhance the capacity of the solvent to incorporate the energy from radiation and to avoid large amount of solvent for the extraction. In case of thermolabile molecules, soft conditions are needed and so the choice will fall on an open system or the vacuum microwave assisted extraction (VMAE) that allows the reduction of the boiling point of the solvent. For compounds that are susceptible of oxidation it has been developed the nitrogen-protected microwave-assisted extraction operating under pressurized inert gas. When the bioactive compounds are susceptible of hydrolysis such as the essential oils, solvent-free microwave-assisted extraction (SFME) is used to avoid the loss/degradation of these products. Moreover, MAE can be associated to ultrasonic energy (ultrasonic/microwave-assisted extraction UMAE) to reduce extraction times and the amounts of solvent leading to an improvement of the yield. Another way to gain time is coupling the extraction step with the analytical one in the dynamic microwave-assisted extraction (DMAE) which operates continuously and automatically. The choice of the solvent is influenced by its ability to absorb the microwave radiation: ethanol, methanol, water and the more selective room temperature ionic liquids are good solvents for MAE. The ratio of solvent to solid is important for improving MAE: if the amount of solvent is too much it absorbs all the energy with a resulting inefficient matrix heating, whereas if the ratio is too low the amount of solvent is not enough to allow the diffusion of the compounds out of the matrix. Also the vessel size is a critical factor because in a little vessel the internal pressure tends to augment and this could mean a degradation of the more delicate molecules.

Another parameter to consider in MAE is the power of extraction: an increased power boosts the temperature reducing the solvent viscosity and leading to a better efficiency, except in case of thermolabile molecules. Microwave-assisted extraction gives several advantages with respect to classical extractive processes such as Soxhlet: MAE allows a gain of time, higher quality and yields [13]. It is also cheaper than supercritical fluid extraction (SFE) and faster than ultrasonic-assisted extraction (UAE). On the other hand, MAE shows some drawbacks: it is more expensive than UAE, less ecofriendly than SFE due to the use of organic solvents, not suitable for thermolabile compounds because the irradiation could promote chemical reactions with the loss of the desirable products, and not efficient when the target molecules and/or the solvent of extraction are non-polar because they do not absorb energy from the source [14]. This technique has never been applied to $S$. repens extraction.

\section{Ultrasound-assisted extraction}

In recent times, ultrasound-assisted extraction has received a great interest to overcome the disadvantages of classical solvent extractions such as little yields and waste of time. UAE is based on the production of ultrasound waves and their transmission throughout the solvent with a resulting cavitation. When the cavitation bubbles collapse, there is a generation of liquid circulation currents and turbulence that improve the mass transfer rate. The fractures formed in the cell wall enhance its permeability and so a bigger amount of solvent can enter into the plant tissues to extract the bioactive metabolites. In order to perform an extraction based on sonochemistry, the choice of solvent becomes an important parameter because its physical properties like polarity, viscosity, vapour pressure and surface tension influence the cavitation 
phenomena. Ethanol, methanol and hexane are very used in UAE, and sometimes water could be added to ethanol, even if its amount must not be too much in order to avoid a decrease in extraction efficiency, probably due to the generation of radicals from the ultrasonic dissociation of water [15]. Other parameters to be considered are the frequency and the power: often the former ranges from 20 to $100 \mathrm{kHz}$ and the latter from 100 to $800 \mathrm{~W}$. Also the power dissipation is a critical factor, because the generation of physical effects like turbulence is directly proportioned to the power dissipated as heat. For the future, the design of reactors based on multiple transducers is needed in order to operate at multiple frequencies and improve the efficacy of UAE. Another problem that currently limits the use of UAE at large scales is the erosion of transducers and their continuous replacement to avoid a decrease in the transmitted energy. Nonetheless, UAE is less expensive than the traditional extractive techniques; it can give high quantities of products without spending time and without using large amounts of solvent. For a better performance, UAE can be also used in combination with other techniques like supercritical fluid process. This technique has never been applied to $S$. repens extraction.

\section{Supercritical fluid extraction}

Supercritical fluid extraction is a novel technique especially used for the recovery of essential oil from plants. SFE is based on the use of carbon dioxide in supercritical phase, which is at low pressure and temperature (74 bar and $32^{\circ} \mathrm{C}$ ): in this state $\mathrm{CO}_{2}$ possesses a polarity similar to pentane and so it is a good candidate for the extraction of lipophilic compounds. Furthermore supercritical $\mathrm{CO}_{2}$ is non toxic, non-flammable, not expensive, and easy to remove in the end of the process (eco-friendly). Operating at low temperature it is possible to obtain in high yield thermolabile compounds like terpenes and terpenoids that normally have their boiling point over $150^{\circ} \mathrm{C}$ and so it is important to work at lower temperatures for preventing their degradation [16]. If the components to extract are polar, a cosolvent like water or ethanol in little percentage $(5-10 \%)$ is needed to increase the extraction quality. When in the plant matrix there are bioactive compounds of different solubility, a method to improve the recovery of all the phytotherapeutics without any loss is the fractionation of the extract [17]. Two strategies could be applied: the multi-step fractionation and the on-line fractionation.

When the multi-step fractionation is performed, there are different successive steps of separation with different conditions in terms of density of $\mathrm{CO}_{2}$ : in the first step we will obtain the fraction of the more soluble compounds such as essential oils, whereas in the second step, increasing $\mathrm{CO}_{2}$ density we will have the recovery of the less soluble components like antioxidants. Moreover, thanks to this strategy we can obtain in the first step the products extracted by the only use of supercritical $\mathrm{CO}_{2}$, while in a second time we can add a cosolvent such as ethanol for the other compounds. The on-line fractionation works, instead, in a cascade depressurization system in order to obtain the precipitation of the several fractions according to their saturation conditions. The particular properties of the supercritical fluid characterized by a low viscosity and a high diffusion make this technique an excellent alternative to the others for the recovery of therapeutic products from plants.

\section{Ionic liquids}

The use of ionic liquid (IL) for analytical purposes has been developed in modern times with advantages in terms of quality and efficacy of extraction. In particular, an ionic liquid consists of a liquid organic salt that selectively interacts with specific polar and non-polar compounds thanks to ion-exchanges, $\pi$-stacking interactions, hydrophobic interactions or hydrogen bonds, improving the selectivity of the extractive method [18]. For example, the interaction of 1-butyl-3-methylimidazolium hexafluorophosphate ([BMIM] $\left.\left[\mathrm{PF}_{6}\right]\right)$ with hydrophilic amino acids enhances the extraction efficiency with respect to a traditional organic solvent extraction. Being ILs applied in several extractive processes such as MAE and UAE, they should be stable enough to resist to the high temperatures through which the technique works. About this matter, tetraalkylammonium cations and imidazolium ions like tetrafluoroborate $\left[\mathrm{BF}_{4}\right]^{-}$, bis(trifluoromethylsulfonyl) imide $\left[\mathrm{NTf}_{2}\right]^{-}$, trifluoromethanesulfonate $\left[\mathrm{CF}_{3} \mathrm{SO}_{3}\right]^{-}$, and hexafluorophosphate $\left[\mathrm{PF}_{6}\right]^{-}$, possess a great thermal stability; moreover, the organic anions have shown to be more stable than the inorganic ones when operating at elevated temperatures. In conclusion, extraction based on ILs represents a good choice to recover in high yields organic and inorganic and metal ions as bioactive components of plants and herbs. This technique has never been applied to $S$. repens extraction.

\section{Enzyme-assisted extraction}

An alternative approach to classical solvent extraction techniques is the enzyme-assisted extraction: this method is innovative and convenient thanks to the fact that the enzymes catalyze reactions in a specific way without operating under strong conditions that could lead to the degradation of the desired products. In addition, proteins like cellulases, hemicellulases and pectinases disrupt cell wall with the hydrolysis of its components leading to a major permeability and allowing an easier release of the metabolites from plants [19]. The application of enzymes such as lipases, proteases, phospholipases, permits to reduce the use of the solvent for the extraction. For oil extraction from plants, cellulase, $\alpha$-amylase and pectinase are the most used enzymes. These proteins can be obtained from 
fungi, bacteria, animals, and vegetables or from genetic engineering methods and, thanks to their selective catalysis, they can be used to recover a specific bioactive compound in high yields and in a "green" approach, without wasting too much energy. Nevertheless, there are some limitations due to the cost of the enzymatic approach, the incomplete disruption of the cell wall and the complicated application in a commercial scale because of the different behaviour of the enzymes according to the environmental circumstances such as the amount of oxygen, the variety of nutrients and the operating temperature. This technique has never been applied to $S$. repens extraction.

\section{Pressurized liquid/fluid extraction}

Pressurized liquid extraction (PLE or PFE in case of a general fluid) is a novel and eco-friendly approach for the recovery of bioactives from plants. This method often requires water as the solvent and so it can keep away from the environmental and health risks due to the use of organic solvents. Operating at high temperature (till $200^{\circ} \mathrm{C}$ ) and pressure (from 35 to 200 bar), PLE improves the quality of the extraction that can be carried out in a dynamic mode in which the solvent is incessantly pumped through the vessel, or in a static mode in which there are more cycles with a continuous replacement of the solvent [20]. At elevated temperatures there is a reduction of the viscosity of the solvent that can better penetrate the matrix extracting the analytes of interest, even if this approach cannot be used for the thermally unstable compounds and it could lead to a co-extraction of other compounds because of the decreased selectivity of extraction at higher temperatures. The elevated pressure permits maintaining the solvent in the liquid phase and the disruption of plant cells wall exerting pressure on the matrix. In place of organic solvents, it is possible to use additives like non-ionic surfactants, antioxidants like ascorbic acid, $\mathrm{CO}_{2}$ to drop aqueous $\mathrm{pH}$ or drying agents. Furthermore, PLE apparatus protects light sensitive and oxygen sensitive products from degradation, and it could be hyphenated with other modern extractive techniques like UAE to improve its efficacy.

\section{Serenoa repens extracts: therapeutic properties and implication for the treatment of $\mathrm{BPH}$}

Natural products recovered from plants and herbs have been using for centuries for the treatment of several pathologies including benign prostatic hyperplasia. Among the phytotherapeutics used for BHP, bioactives extracted from the fruit of the American dwarf palm S. repens is the most widespread thanks to its safety, tolerability profile, and clinical benefits. The composition of free fatty acids, methyl and ethyl esters, long chain esters and glycerides found in $S$. repens extracts $(\mathrm{SrE})$ is different from a brand to another according to the extractive strategy used [21].
Although the specific mechanism of action of $\mathrm{SrE}$ has not been completely understood yet, it has been reported that the therapeutic agents could exert an inhibitory activity towards $5 \alpha$-reductase, in addition to pro-apoptotic, anti-estrogenic and anti-inflammatory properties [22].

In the past, two reviews compared a large number of different brands of marketed S. repens extracts on the basis of the quali-quantitative composition in free fatty acids and their esterified forms [23] and on their corresponding inhibitory activity against the two isoforms of $5 \alpha$-reductase [24,25]. Results were contrasting among these natural products (and above all among the batches of the same product) and, consequently, their clinical efficacy could be recognized different as well.

The database (Pubmed, Scifinder) investigation has been directed towards the most recent and relevant studies regarding the biological properties and therapeutic applications of $S$. repens extracts and the comparison among these commercial products. We chose "Serenoa repens" and "Serenoa repens extraction" terms for the bibliographic research. As a matter of this, we collected in Table 2 studies on different extracts and active principles of $S$. repens to demonstrate how, despite the pharmacological interest in this plant for the treatment of lower urinary tract symptoms, little is known about its phytochemical/pharmacological complexity and a better standardization could improve the interchangeability among these brand products.

From this synoptic summary it is possible to extrapolate that:

- As regards Sabalselect ${ }^{\oplus}$ by Indena (supercritical carbon dioxide extract, SFE), despite the high content in free fatty acids, the quantitative composition in its single components depends on the natural source variability. The major findings of this study are that lauric acid, oleic acid, myristic acid and linoleic acid, the major constituents of SFE, as well as SFE itself, actively bound to pharmacologically relevant ( $\alpha 1$-adrenergic, muscarinic and 1,4-DHP) receptors in rat brain, and significantly inhibited $5 \alpha$-reductase activity in rat liver. In addition, these components and the whole extract were shown to inhibit specific binding of $\left[{ }^{3} \mathrm{H}\right]$ prazosin in rat brain. Based on their $\mathrm{IC}_{50}$ values, the affinity for $\alpha 1$-adrenergic, 1,4-DHP, and muscarinic receptors displayed by linoleic acid, oleic acid, and myristic acid was 1.3-4.5 times greater than that of SFE. Conversely, the receptor binding activity of lauric acid and palmitic acid was similar to that of SFE. In general, the receptor binding activity of unsaturated fatty acids tended to be greater than that of saturated fatty acids (correlation of the pharmacological activity with the degree of 
Table 2 Different extracts of different brands of Serenoa repens discussed and compared in this review

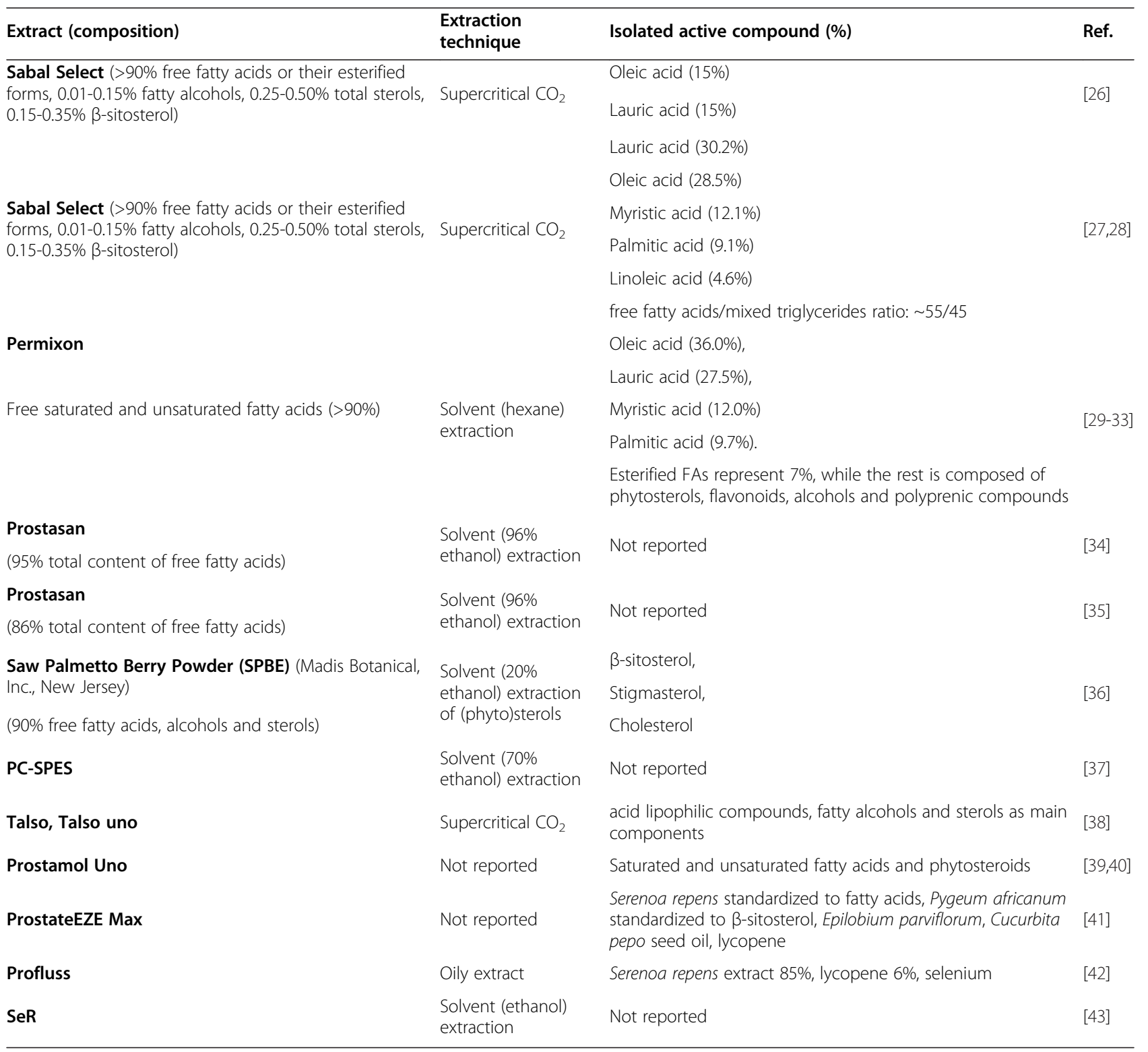

unsaturation and bond length). SFE, lauric acid, oleic acid, myristic acid and linoleic acid inhibited $5 \alpha$-reductase activity in a concentration-dependent manner. The inhibitory effect of each fatty acid was similar or slightly more potent than that of SPE. Consistent with these results, Raynaud et al. reported that palmitic acid was inactive in the inhibition of $5 \alpha$-reductase [25]. The inhibitory effect on $5 \alpha$-reductase activity by each fatty acid was roughly similar to their affinity for pharmacologically relevant receptors [26,27]. In a recent research, the effect on rat prostate gland contractility of this extract was evaluated after fractioning. The inhibition of prostatic smooth muscle contractions was preferentially induced by the ethyl acetate fraction (enriched in fatty acids) via a non-specific mechanism (not involving the inhibition of protein kinase $\mathrm{C}$, myosin light chain kinase and Rho kinase) [28].

- Permixon is the most studied extract in the literature both regarding its anti-proliferative activity and its anti-inflammatory ability. The former activity has been demonstrated, for the hexanic extract, against a large number of prostate carcinoma cell lines ( $\mathrm{PC} 3$ and $\mathrm{LNCaP}$ ) where it caused growth arrest and apoptosis at $50-80 \mu \mathrm{g} / \mathrm{mL}$ for $24-48 \mathrm{~h}$ (but not in MCF7 breast cancer cells). Treatment of cells with $100 \mu \mathrm{g} / \mathrm{mL}$ for $4 \mathrm{~h}$ resulted in morphological changes with massive vacuolization and swelling 
(derangement of the ultrastructure with major changes in membrane composition and function). Apoptosis seemed to depend on the intrinsic pathway, which appears to be triggered by opening of the mitochondrial PTP, a high-conductance channel that is involved in many forms of cell death, and complete release of mitochondrial TMRM (early mitochondrial depolarization and loss of membrane potential). Cell-cycle analysis showed the presence of a sub-G1 peak, a decreased G0/G1 peak and an accumulation of cells in G2/M phase after $48 \mathrm{~h}$ of treatment $[29,30]$.

With respect to the latter mechanism of action, different research groups highlighted the anti-inflammatory property of this plant. Multiple inflammation functional systems, such as Cytokines family, Glucocorticoid/PPAR signalling, MAPK signalling, TNF superfamily, and COX/LOX pathways, seemed to be modulated by LSESr treatment. Recently, Latil et al. [31] have studied how this biological property could be ascribed only to the hexanic extract of this plant and not to the supercritical $\mathrm{CO}_{2}$ extract. Both of the tested extracts belonged to six different batches of the same plant at Pierre Fabre Plantes et Industrie. Results showed that the hexanic extract was responsible of a strong attenuation of a large number of inflammation mediators and markers. Moreover, inhibition of MCP-1/CCL2 mRNA expression in a concentrationdependent manner has been registered only for the hexanic extract, whereas the supercritical $\mathrm{CO}_{2}$ extract was not endowed with this inhibitory effect. This is the only one example in the literature of a direct comparison of the different pharmacological profile associated to two extraction techniques showing the impact of this procedures on the quality/ efficacy of phytotherapeutic products [31-33];

- Prostasan ${ }^{\bullet}$ has been also studied both for its antiproliferative and anti-inflammatory activities (as an ethanolic extract). Comparison of the obtained results with respect to Permixon ${ }^{\oplus}$ led to similar results in terms of low cytotoxicity against normal cells, dose-dependent reduction of cellular growth (especially in AR-positive prostate and ER-positive breast cancer cells), apoptosis induction, inhibition of IL-12, MCP-1 and GM-CSF secretion and, consequently, decreased inflammatory processes and production of cytokine pro-inflammatory from macrophages. The content in free fatty acids is almost comparable to that of Permixon ${ }^{\bullet}$. Moreover, inhibitory effects on the epithermal growth factor (EGF) and the Gram-negative bacteria cell wall component LPS-induced proliferation of prostatic cells PC-3 were observed with this extract. In the case of EGF, the mechanism involves competition for the EGF receptor. LPS exerts a milder but still significant induction on proliferation of prostate cells, supporting the role of bacterial infection in the origin of BPH. The mechanism behind $S$. repens extract effecting LPS actions on prostatic cells remains to be elucidated since it does not apparently affect Toll-like receptor 4 intracellular signalling [34,35];

- Saw Palmetto Berry Powder (SPBE) biological activity has been investigated with respect to its phytosterols content. With increasing concentration, the authors observed a reduction in cell growth compared to control cells in the following order of substance effectiveness: $\mathrm{SPBE}>\beta$-sitosterol $>$ stigmasterol, and an increase in cell growth with rising cholesterol concentration on prostate cancer cells (DU145). Analysis of cell cycle regulating proteins (p53, p27, p21) and 2D traction microscopy were also performed. p53 increased after treatment with this extract, whereas p27 and p21 decreased. This report justifies the administration of the entire phytocomplex to ensure a proper pharmacological efficacy not limiting the interest only to free fatty acids [36];

- PC-SPES is a combination of herbs containing flavonoids, alkaloids, polysaccharides, amino acids, and trace minerals. The 8 herbs used were chrysanthemum, isatis, licorice, Ganoderma lucidum, Panax pseudo-ginseng, Rabdosia rubescens, saw palmetto, and skullcap. PC-SPES mediated an anti-proliferative effect on prostate cancer cells (LNCaP, DU145, and PC3) in vivo and in vitro, induced apoptosis of LNCaP cells in a dose- and time-dependent manner and reduced prostate specific antigen (PSA) or AR levels in LNCaP cells and in more than $80 \%$ of individuals with prostate cancer. In addition in the same cell line, saw palmetto might inhibit cell growth down-regulating basal and DHT- or IL-6-induced PSA expression in cytoplasmic protein and AR expression in nuclear proteins. Previous studies have demonstrated that STAT3 signalling has a critical role in the tumour formation of prostate cancer and IL- 6 treatment results in the activation of STAT3 in prostate cancer cells. This extract down-regulated the IL-6-induced level of the phosphorylated form of STAT3 in LNCaP cells blocking this pathway and markedly inhibiting the growth of LNCaP cells [37];

- The SG 291 extract (Talso, Talso uno) was analyzed by gas chromatography and investigated for its dual inhibitory influence on cyclooxygenase (COX, $\left.\mathrm{IC}_{50}=28.1 \mu \mathrm{g} / \mathrm{mL}\right)$ and 5-lipoxygenase (5-LOX, $\left.\mathrm{IC}_{50}=18 \mu \mathrm{g} / \mathrm{mL}\right)$. After alkaline hydrolysis, ether extraction and preparative TLC the SG 291 extract 
was separated in three fractions containing acid lipophilic compounds (A), fatty alcohols (B) and sterols (C). Only fraction A inhibited COX and 5-LOX as the native SG 291 extract, whereas the fractions $\mathrm{B}, \mathrm{C}$ and $\beta$-sitosterol showed no inhibitory effect on both enzymes [38].

- Prostamol Uno (Berlin-Chemie AG/Menarini Group) was shown to possess anti-inflammatory and antiedematous effects reducing the proliferation of prostatic epithelium. Moreover, its pharmacological activity in rats with $\mathrm{BPH}$ was compared to that of a complex of peptides isolated from the cattle prostate. The results showed that both treatments reduced the acinar epithelial area in this experimental model, but the response to $S$. repens extract was characterized by an enhanced stromal/epithelial proportion [39]. In addition, the safety and tolerability of this extract have been evaluated in two dosage regimes in experimental animals [40].

- ProstateEZE Max (Caruso's Natural Health) is an orally dosed herbal preparation containing $S$. repens (660 mg/day), among other prostatotropic agents of natural origin (Cucurbita pepo, Epilobium parviflorum, lycopene and Pygeum africanum). It has been studied in a short-term phase II randomized double-blind placebo controlled clinical trial to evaluate its efficacy and safety [41]. This combination of herbal extracts behaved as an effective treatment in the management of symptoms of BPH.

- Profluss ${ }^{\circ}$ by Konpharma: to evaluate its efficacy on prostatic chronic inflammation, 168 subjects affected by LUTS due to bladder outlet obstruction were enrolled and subjected to Profluss with or without $\alpha$-blockers treatment ("Flogosis And Profluss in Prostatic and Genital Disease" (FLOG) study). At follow-up there were statistical significant reductions of extension and grading of flogosis (mean values of CD20, CD3, CD68, and PSA). This product may have an anti-inflammatory activity that could be of interest in the treatment of PCI in BPH [42].

- SeR alcoholic extract, provided by Bernett, has been recently studied (alone and in association with selenium and lycopene) for the impact on the bax/ bcl-2 ratio, caspase- 3 activity, IAPs and survivin expression, and cytokines production in prostatic specimens from BPH patients. These analyses suggested that the impairment in the extrinsic pathway does not contribute to the cell death program in $\mathrm{BPH}$, that the administration of SeR, either alone or in association, markedly mitigated survivin expression. Moreover, the expression of IL-6 was reduced preventing the histological features of BPH and inhibiting growth by $43.3 \%$ [43].

\section{Review and conclusions}

Benign prostate hyperplasia is one of the most common diseases in male population. In addition to pharmacological therapy with $\alpha$-blockers or $5 \alpha$-reductase inhibitors, also bioactive compounds derived from plants play an important role in the treatment of $\mathrm{BPH}$ associated to LUTS. Despite the benefits obtained from SrE, the variety of the extractive techniques and strategies makes one extract different from another in terms of bioactives composition and this could affect the quality and the clinical effects of natural therapies of different brands even if derived from the same plant. Thus, the clinical and biological activities of one preparation cannot be extrapolated to other preparations of the same plant source. Moreover, standardization of the composition through alternative and more reproducible techniques is warranted due to the complex pharmacological profile of the whole phytocomplex of S. repens. Results from different clinical trials must be compared strictly according to the same validated extraction technique and/or content in active principles.

At this time, few studies made a comparison among these different extracts. The solvent (hexane) extraction of lipidosterolic composition from $S$. repens is the most investigated in clinical and experimental trials although further large comparative trials should explore the possible clinical influence of the different extractions processes.

\section{Competing interests}

We disclose any conflict of interest such as consultancies, stock ownership or other equity interests, patents received and/or pending, or any commercial relationship which might be in any way considered related to the submitted article.

\section{Authors' contributions}

CDM conception and design, general supervision. SC conception and design, analysis and interpretation of data drafting of the manuscript. AG collection of data, drafting of the manuscript. GBDP conception and design, critical revision for intellectual content. $\mathrm{CL}$ general supervision, collection of data, CDN conception and design, general supervision, critical revision for intellectual content. All authors have made a significant contribution to the paper, and have read and approved the final draft. The work has not already been published and has not been submitted simultaneously to any other journal.

\section{Acknowledgment}

We thank Pierre Fabre for supporting and funding the study.

\section{Author details}

${ }^{1}$ Department of Drug Chemistry and Technologies, Sapienza University of Rome, P.le A. Moro 5, Rome 00185, Italy. ${ }^{2}$ Department of Obstetrics, Gynecology and Urology, Sapienza University of Rome, Viale del Policlinico 155, Rome 00161, Italy. ${ }^{3}$ Department of Urology, Ospedale Sant'Andrea, Sapienza University of Rome, Via di Grottarossa 1035/1039, Rome 00189, Italy.

Received: 27 January 2014 Accepted: 28 July 2014

Published: 11 August 2014

\section{References}

1. De Nunzio C, Aronson W, Freedland S, Giovannucci E, Parsons JK: The correlation between metabolic syndrome and prostatic diseases. Eur Urol 2012, 61:560-571. 
2. Oelke M, Bachmann A, Descazeaud A, Emberton M, Gravas S, Michel MC, N'dow J, Nordling J, de la Rosette JJ: EAU guidelines on the treatment and follow-up of non-neurogenic male lower urinary tract symptoms including benign prostatic obstruction. Eur Urol 2013, 64:118-140.

3. Miano R, De Nunzio C, Asimakopoulos T, Germani S, Tubaro A: Treatment options for benign prostatic hyperplasia in elderly men. Med Sci Monit 2008, 14:94-102.

4. Cornu JN, Cussenot O, Haab F, Lukacs B: A widespread population study of actual medical management of lower urinary tract symptoms related to benign prostatic hyperplasia across Europe and beyond official clinical guidelines. Eur Urol 2010, 58:450-456.

5. Fourcade RO, Théret N, Taïeb C: Profile and management of patients treated for the first time for lower urinary tract symptoms/benign prostatic hyperplasia in four European countries. BJU Int 2008, 101:1111-1118.

6. Suter A, Saller R, Riedi E, Heinrich M: Improving BPH symptoms and sexual dysfunctions with a saw palmetto preparation? Results from a pilot trial. Phytother Res 2013, 27:218-226

7. MacDonald R, Tacklind JW, Rutks I, Wilt TJ: Serenoa repens monotherapy for benign prostatic hyperplasia (BPH): an updated Cochrane systematic review. BJU Int 2012, 109:1756-1761.

8. Azimi H, Khakshur AA, Aghdasi I, Fallah-Tafti M, Abdollahi M: A review of animal and human studies for management of benign prostatic hyperplasia with natural products: perspective of new pharmacological agents. Inflamm Allergy Drug Targets 2012, 11:207-221.

9. Tacklind J, Macdonald R, Rutks I, Stanke JU, Wilt TJ: Serenoa repens for benign prostatic hyperplasia. Cochrane Database Syst Rev 2012, 12:CD001423.

10. Lowe FC: Phytotherapy in the management of benign prostatic hyperplasia. Urology 2001, 58:71-77.

11. Schantz MM, Bedner M, Long SE, Molloy JL, Murphy KE, Porter BJ, Putzbach K, Rimmer CA, Sander LC, Sharpless KE, Thomas JB, Wise SA, Wood LJ, Yen $J$ H, Yarita T, NguyenPho A, Sorenson WR, Betz JM: Development of saw palmetto (Serenoa repens) fruit and extract standard reference materials. Anal Bioanal Chem 2008, 392:427-438.

12. Chan $\mathrm{CH}$, Yusoff $\mathrm{R}$, Ngoh GC, Kung FWL: Microwave-assisted extractions of active ingredients from plants. J Chromatogr A 2011, 1218:6213-6225.

13. Capitani D, Sobolev AP, Delfini M, Vista S, Antiochia R, Proietti N, Bubici N, Ferrante G, Carradori S, De Salvador FR, Mannina L: NMR methodologies in the analysis of blueberries. Electrophoresis 2014. doi:10.1002/elps.201300629.

14. Zhang HF, Yang XH, Wang Y: Microwave-assisted extraction of secondary metabolites from plants: current status and future directions. Trends Food sci Tech 2011, 22:672-688.

15. Shirsath SR, Sonawane SH, Gogate PR: Intensification of extraction of natural products using ultrasonic irradiations - a review of current status. Chem Eng Process 2012, 53:10-23.

16. Fornari T, Vicente G, Vàzquez E, Garcia-Risco MR, Reglero G: Isolation of essential oil from different plants and herbs by supercritical fluid extraction. J Chromatogr A 2012, 1250:34-48.

17. Akanda MJ, Sarker MZ, Ferdosh S, Manap MY, Ab Rahman NN, Ab Kadir MO: Applications of supercritical fluid extraction (SFE) of palm oil and oil from natural sources. Molecules 2012, 17:1764-1794.

18. Tang B, Bi W, Tian M, Row KH: Application of ionic liquid for extraction and separation of bioactive compounds from plants. $J$ Chromatogr $B$ 2012, 904:1-21.

19. Puri M, Sharma D, Barrow CJ: Enzyme-assisted extraction of bioactives from plants. Trends Biotechnol 2012, 30:37-44

20. Mustafa A, Turner C: Pressurized liquid extraction as a green approach in food and herbal plants extraction: A review. Anal Chim Acta 2011, 703:8-18.

21. Geavlete P, Multescu R, Geavlete B: Serenoa repens extract in the treatment of benign prostatic hyperplasia. Ther Adv Urol 2011, 3:193-198.

22. Buck AC: Is there a scientific basis for the therapeutic effects of Serenoa repens in benign prostatic hyperplasia? mechanisms of action. J Urol 2004, 172:1792-1799.

23. Habib FK, Wyllie MG: Not all brands are created equal: a comparison of selected components of different brands of Serenoa repens extract. Prostate Cancer Prostatic Dis 2004, 7:195-200.

24. Scaglione F, Lucini V, Pannacci M, Caronno A, Leone C: Comparison of the potency of different brands of Serenoa repens extract on 5a-reductase types I and II in prostatic co-cultured epithelial and fibroblast cells. Pharmacology 2008, 82:270-275.
25. Raynaud JP, Cousse H, Martin PM: Inhibition of type 1 and type 2 5alpha-reductase activity by free fatty acids, active ingredients of Permixon. J Steroid Biochem Mol Biol 2002, 82:233-239.

26. Abe M, Ito $Y$, Suzuki A, Onoue $S$, Noguchi H, Yamada S: Isolation and pharmacological characterization of fatty acids from saw palmetto extract. Anal Sci 2009, 25:553-557.

27. Abe M, Ito Y, Oyunzul L, Oki-Fujino T, Yamada S: Pharmacologically relevant receptor binding characteristics and 5a-reductase inhibitory activity of free fatty acids contained in Saw Palmetto extract. Biol Pharm Bull 2009, 32:646-650.

28. Chua T, Eise NT, Simpson JS, Ventura S: Pharmacological characterization and chemical fractionation of a liposterolic extract of saw palmetto (Serenoa repens): effects on rat prostate contractility. J Ethnopharmacol 2014, 152:283-291.

29. Baron M, Mancini E, Caldwell A, Cabrelle P, Bernardi F, Pagano F: Serenoa repens extract targets mitochondria and activates the intrinsic apoptotic pathway in human prostate cancer cells. BJUI 2009, 103:1275-1283

30. Petrangeli $E$, Lenti L, Buchetti B, Chinzari P, Sale P, Salvatori L, Ravenna L, Lococo E, Morgante E, Russo A, Frati L, Di Silverio F, Russo MA: Lipidosterolic extract of Serenoa repens (LSESr, Permixon ${ }^{\circledR}$ ) treatment affects human prostate cancer cell membrane organization. J Cell Physiol 2009, 219:69-76.

31. Latil A, Libon C, Templier M, Junquero D, Lantoine-Adam F, Nguyen T: Hexanic lipidosterolic extract of Serenoa repens inhibits the expression of two key inflammatory mediators, MCP-1/CCL2 and VCAM-1, in vitro. BJUI 2012, 110:E301-E303.

32. Silvestri I, Cattarino S, Aglianò AM, Nicolazzo C, Scarpa S, Salciccia S, Frati L, Gentile V, Sciarra A: Effect of Serenoa repens (Permixon ${ }^{\circledR}$ ) on the expression of inflammation-related genes: analysis in primary cell cultures of human prostate carcinoma. J Inflammation 2013, 10:11-19.

33. Sirab N, Robert G, Fasolo V, Descazeaud A, Vacherot F, de la Taille A, Terry S: Lipidosterolic extract of Serenoa repens modulates the expression of inflammation related-genes in benign prostatic hyperplasia epithelial and stromal cells. Int J Mol Sci 2013, 14:14301-14320.

34. Hostanska K, Suter A, Melzer J, Saller R: Evaluation of cell death caused by an ethanolic extract of Serenoae repentis fructus (Prostasan ${ }^{\oplus}$ ) on human carcinoma cell lines. Anticancer Res 2007, 27:873-882.

35. Iglesias-Gato D, Carsten T, Vesterlund M, Pousette A, Schoop R, Norstedt G: Androgen-independent effects of Serenoa repens extract (Prostasan) on prostatic epithelial cell proliferation and inflammation. Phytother Res 2012, 26:259-264.

36. Scholtysek C, Krukiewicz AA, Alonso JL, Sharma KP, Sharma PC, Goldmann WH: Characterizing components of the Saw Palmetto Berry Extract (SPBE) on prostate cancer cell growth and traction. Biochem Biophys Res Commun 2009, 379:795-798.

37. Yang Y, Ikezoe T, Zheng Z, Taguchi H, Koeffler HP, Zhu WG: Saw Palmetto induces growth arrest and apoptosis of androgen-dependent prostate cancer LNCaP cells via inactivation of STAT 3 and androgen receptor signaling. Int J Oncol 2007, 31:593-600.

38. Breu W, Hagenlocher M, Redl K, Tittel G, Stadler F, Wagner H: Antiinflammatory activity of sabal fruit extracts prepared with supercritical carbon dioxide. In vitro antagonists of cyclooxygenase and 5-lipoxygenase metabolism. Arzneimittelforschung 1992, 42:547-551.

39. Duborija-Kovacevic N, Jakovljevic V, Sabo A, Tomic Z, Pajovic B, Perovic D: Tolerability and toxicity of lipidosterolic extract of American dwarf palm Serenoa repens in Wistar rats: well-known extract, new insight. Eur Rev Med Pharmacol Sci 2011, 15:1311-1317.

40. Borovskaya TG, Fomina TI, Ermolaeva LA, Vychuzhanina AV, Pakhomova AV, Poluektova ME, Shchemerova YA: Comparative evaluation of the efficiency of prostatotropic agents of natural origin in experimental benign prostatic hyperplasia. Bull Exp Biol Med 2013, 155:67-70.

41. Coulson S, Rao A, Beck SL, Steels E, Gramotnev H, Vitetta L: A phase II randomised double-blind placebo-controlled clinical trial investigating the efficacy and safety of ProstateEZE max: a herbal medicine preparation for the management of symptoms of benign prostatic hypertrophy. Comp/ Ther Med 2013, 21:172-179.

42. Morgia G, Cimino S, Favilla V, Russo Gl, Squadrito F, Mucciardi G, Masieri L, Minutoli L, Grosso G, Castelli T: Effects of Serenoa repens, selenium and lycopene (Profluss ${ }^{\circledR}$ ) on chronic inflammation associated with benign prostatic hyperplasia: results of "FLOG" (flogosis and Profluss in prostatic 
and genital disease), a multicentre italian study. Int Braz J Urol 2013, 39:214-221.

43. Minutoli L, Altavilla D, Marini H, Rinaldi M, Irrera N, Pizzino G, Bitto A, Arena S, Cimino S, Squadrito F, Russo Gl, Morgia G: Inhibitors of apoptosis proteins in experimental benign prostatic hyperplasia: effects of Serenoa repens, selenium and lycopene. J Biomedical Sci 2014, 21:19.

doi:10.1186/1471-2490-14-63

Cite this article as: De Monte et al: Modern extraction techniques and their impact on the pharmacological profile of Serenoa repens extracts for the treatment of lower urinary tract symptoms. BMC Urology 2014 14:63.

\section{Submit your next manuscript to BioMed Central and take full advantage of:}

- Convenient online submission

- Thorough peer review

- No space constraints or color figure charges

- Immediate publication on acceptance

- Inclusion in PubMed, CAS, Scopus and Google Scholar

- Research which is freely available for redistribution 